\title{
Uses and Gratifications of Online News among Young Adults in Bahrain
}

\begin{abstract}
By Hatem Alsridi ${ }^{*}$
This study examines the use of local and Arab news websites among young adults in Bahrain. It identifies the patterns of use, the reasons of choices, and the factors that influence these choices and highlights the potential difficulties, if any, preventing users from finding gratifications in their news practices. A survey was administered to a random sample of 522 Bahraini young adults aged 18 to 29 years to achieve the objectives of the study. The study found that online news consumption by young adults in Bahrain is on the increase, is accessed in particular by the mobile phone at all times and in all places, however, only a short time is allocated for this use, and is focused more on local news. The study also showed that young Bahrainis have become active users, relying on multiple patterns of use, and that their activity is not confined to reading the news but have a feeling of belonging to a community of users (Breton \& Proulx, 2002). They also engage in parallel interactive activities that support their position through employing Internet technology from the perspective of uses and gratifications theory (Ruggiero, 2000).
\end{abstract}

Keywords: Bahrain, online news, news consumption, uses and gratifications, young adults

\section{Introduction}

International Telecommunication Union (ITU) statistics indicate that 93.5\% of Bahrain's population uses the Internet, and the number of Internet subscriptions via the mobile phone per hundred inhabitants is estimated at $131.8 \%$ (ITU, 2015). This is a significant indicator as it has bearing on the study and analysis of use patterns and gratifications among Bahraini young adults with regard to their online news consumption. However, despite the high percentage of Internet users in Bahrain, research and studies on the uses of the Internet in general and online news in particular are still limited ${ }^{1}$.

There is no doubt that communication technology, including the Internet, has a strong effect on the lives of young adults compared with the rest of technological innovations. Media content has influenced, in particular, the beliefs, attitudes and behavior of young adults (Roberts \& Foehr, 2004). Most studies agree that young adults are one of the most interested user groups in the Internet, as they tend to exercise freedom and control provided by the media experience on the Internet. Young adults remain the most open category that accepts technological developments and the multiplicity of news sources. Young adults exercise options in the use of the media, based on the nature of their personalities, the requirements of their social upbringing, and the identification of their personal needs (Arnett, 1995).

Thus, it is very important that studies and research should be conducted in this context to analyze young adults' employment of the new technology tools and

\footnotetext{
${ }^{*}$ Assistant Professor, Department of Mass Communication, University of Bahrain, Bahrain.

${ }^{1}$ There are no specialized research centers, in Bahrain, that carry out opinion polls on the use of media.
} 
their cultural, media and news implications. It is also important to understand the new behavior resulting from these uses and their impact on the development of their social and cultural environment.

\section{Literature Review}

The World Internet Project (2016) indicated that young adults in North Africa and the Middle East consider television and the Internet to be the most important sources of news. The young adults of the Arab Gulf states, which enjoy a high rate of connection to the Internet, consider television and the Internet as having the same credibility as sources of news, unlike other countries which have less connection to the Internet and consider television as more credible than the Internet as a news source. Moreover, the Media Use in the Middle East Report (2016), pointed out that $84 \%$ of young adults use the news on the Internet, $40 \%$ of them use it every day with males more than females. The use is higher among those with higher education (88\%) compared with those with secondary education $(82 \%)$, preparatory $(76 \%)$ or primary $(60 \%)$ education. As for the degree of confidence in the social media networks as a source of news, the audience aged 18-24 years is more confident (75\%) than those aged 45 years and older $(40 \%)$.

Social media networks at the international level have become one of the most important news sources. Facebook is the most important social network in terms of searching for, reading, viewing and sharing the news (Newman, Fletcher, Levy $\&$ Kleis, 2016). Furthermore, young adults consider social media (28\%) as their first source of news, compared with TV (24\%). A similar study, carried out on the use of social media networks in the Gulf Cooperation Council (GCC), confirms that Facebook is the most used social network in all areas (Reyaee and Ahmed, 2015). Gulf students are considered very active users regarding the use of local news online as most of them have published local news via Twitter, have contributed to discussions on the Internet, have sent others links to local news via e-mail, and have commented on the local news online (Elareshi, Ziani \& Gunter, 2014). A study on Qataris' use of the media indicated that Qatari users have increased confidence in the different Internet platforms, which provide them with information and news (Meeds, 2015).

According to the Arab Young Survey (2016), social media contributes to the way Arab young adults access the news, as $32 \%$ said they would get daily news electronically, $29 \%$ would watch TV, and $7 \%$ would read newspapers. The application WhatsApp is considered as the most popular social networking platform for Arab young adults, given that 2 of 3 people $(62 \%)$ use it daily, followed by Facebook (55\%), YouTube (33\%), Twitter (28\%) and Instagram (28\%).

The mobile phone has become the most important device used to access this news among university students in the GCC (Zayani, Elareshi \& Gunter, 2015). The GCC university students are considered active users of the mobile phone to gain access to local news and receive local breaking news alerts. In addition, they practice parallel activities to the use of the news, including participation and 
commenting on them, as well as the use of e-mail, and participation in social media networks. However, in spite of the weakness of Internet use in the Arab countries in general, online news consumption is the main activity of the users, after the research and education activities and entertainment (Alshehri, 2000).

A study by Strategy \& Group (Understanding the Arab Digital Generation, 2012) on digital lifestyles of Arab young adults regarding their use of digital technology showed that $83 \%$ of young adults use the Internet daily, $40 \%$ use the Internet at least 5 hours a day, and $61 \%$ spend more than two hours a day on social media networks, while $78 \%$ prefer the Internet to TV.

The Internet, as media, has become one of the most important trends, in terms of the size of the audience. In addition, many of the features that characterize online news have been used to a large extent. As far as innovation and publishing theory are concerned, online news represents a great potential to promote further adoption in the coming years (Nguyen, Ferrier, Western \& Mcky, 2005).

\section{Theoretical Framework}

The uses and gratifications theory has been considered a logical development for the various questions and queries associated with the impact of the media on audiences since the middle of last century. Whereas the functional approach focused its research on media effects on individuals, the theory of uses and gratifications sheds more light on the subject of individual use of the media (Alsridi, 2001). This theory has gained more support, thanks to the work of Blumler and Katz (1974) on the use of mass media in the framework of analysis and study of the needs and gratifications of the audience. It contributes to the understanding and analysis of user behavior through knowledge of the benefits obtained through media experience, the uses that he actually develops and the gratifications that benefit from within his uses of the media (Dominique, 1994). From the perspective of uses and gratifications theory, the behavior of the audience of the media can be interpreted or conceived through the study of the social and psychological origins of the needs generated by the media expectations (Chyi \& Larosa, 1999). As a result, this theory has been used as a theoretical framework in most studies and research on communication (Lin, 1999).

Elliott and Rosemberg (1987) consider that the study of the motives of the audience for the use of a particular type of communication tool is made through this theory whenever a new communication technology is introduced. Ruggiero (2000) considers media and communication technology features, especially the Internet, as tools and sources of news. He argues that these have increased the support and enhancement of the uses and gratifications theory, where the interactive features, navigation, and the choice of use time that characterize the electronic media are new features that make the user an active element who knows what to use and determines the elements that contribute to satisfying his gratifications.

The theory of uses and gratifications, including its scientific dimensions and current concept, represents the theoretical framework of this study that seeks to identify patterns of young adults' use of online news in the Kingdom of Bahrain and the extent to which they are satisfied through these uses. 


\section{Methodology}

To achieve the aims of the study, a questionnaire was prepared, reviewed and approved by two members of the Research Committee in the Mass communication Department at the University of Bahrain. The questionnaire was pilot-tested on 20 male and female young adults in the 18-29 age group. In fact, the term "young adults" generally refers to those over 18 . This category is extended in some studies to 29. As a result, some of the questions that seemed incomprehensible were modified, and a new question was added to the hypothesis about the use of online news. The questionnaire was then distributed to a random sample of young Bahrainis in the 18-29 years age group. The survey questionnaire was distributed electronically via Survey Monkey software $(\mathrm{N}=381)$ and directly in paper copies $(\mathrm{N}=141)$ in order to give an opportunity to all participants to fill in the form through the method of their choice. The Initial data comprised 522 respondents, who represented about $6 \%$ of the total number of Bahraini young adults within the 18-29 age group, according to official statistics of the population issued by the Information and E-Government Authority of the Kingdom of Bahrain (2016). The data was collected in the period between December 19, 2016 and February 8, 2017. In the verification process, 18 respondent forms were excluded because they did not meet the scientific standards. Another 60 respondent forms were also excluded because they did not use online news. The final sample included 444 respondents for whom participation was on a voluntary and anonymous basis.

The final sample of the study comprised $70 \%$ females and $30 \%$ males. It included also $59 \%$ of them at the bachelor's level, $32 \%$ at the high school level, and the rest are between the diploma (6\%) and master's $(3 \%)$ level. The questionnaire includes 24 questions. The aim of the questionnaire in this study, which falls under the uses and gratifications theory, is to identify the reasons for the online news consumption by young adults in Bahrain, and the degree of their benefit from news types. Moreover, the study aims to examine their patterns of interaction with online news; their assessment of their experiences in the use of news; the extent of their satisfaction with all news websites they use, and their understanding of the potential difficulties that hinder the success of their experiences with online news.

As for the questionnaire processing and analysis of the results, the print forms along with the electronic forms were included in the Survey Monkey software. All the data were put in the form of an Excel file that included the final responses. A deeper analysis of the results of the Excel file was carried out using SPSS (Statistical Product and Service Solutions) software. Various descriptive statistics were employed.

\section{Findings}

A small percentage of respondents (12\%) expressed their lack of interest in using online news, despite their use of the Internet. The respondents attribute this to many reasons, most important of which is their access to news in other media sources (58\%), and lack of confidence in the news on the Internet 
$(25 \%)^{2}$. However, the Reuters Institute Digital News Report (2016) states that mainstream media, particularly television, are still able to compete with the Internet, as a source of news (Newman et al., 2016).

Fewer respondents said that their lack of interest in using online news is due to the fatigue caused by reading the news from the screen (17\%), which is in line with the results of previous similar studies that stated that the user's reading slows down by $25 \%$ when reading from the screen (Nielsen, 1999). In addition, it affects the depth of reading, causes less remembering and poor sleep (Myrberg \& Wiberg, 2015). Another reason for lack of interest in online news is the lack of sufficient time to read the news when using the Internet (17\%).

The exclusive use of the Internet as a new media, without interest in the news as part of online media practices proves the contribution of the theory of uses and gratifications to creating an active user model that can develop a variety of responses or reactions to the media (Dominique, 1994). This is in contrast with previous studies and theories in behavioral science (John Broadus Watson), in the psychology of the crowd (Gustave Le Bon), and in the theory of conditioning (Ivan Pavlov), which all support the idea of direct and automatic effect of mass communication on the individual (Table 1).

Table 1. Reasons for Not Using Online News

\begin{tabular}{|l|c|c|}
\hline & Frequency & Percent \\
\hline Accessing news from other sources is enough & 28 & 58 \\
\hline I do not trust the news on the Internet. & 12 & 25 \\
\hline Reading the news on the screen is tiring & 8 & 17 \\
\hline $\begin{array}{l}\text { I do not have enough time to read the news when I am using } \\
\text { the Internet }\end{array}$ & 8 & 17 \\
\hline Other & 8 & 17 \\
\hline
\end{tabular}

\section{Increased Interest in Using Local Online News}

Within the question related to identifying the most important news websites that are used by the respondents, the researcher selected ten news websites, six of which are local, representing the official websites of the main Bahraini newspapers (Akhbar Al-Khaleej, Al-Wasat, Al-Ayam, Al-Watan, Al-Bilad), in addition to the Bahrain News Agency website (BNA), and four international ones (Al-Jazeera Net, Al-Arabiya Net, Al-Sharq Al-Awsat, Al-Arab). An open question was also added concerning the other news websites that are used outside the pre-selected list. The BNA website is the most important and most popular means of electronic media in terms of use (47\%), followed Al-Wasat newspaper (44\%) and Al-Ayam newspaper (40\%) and Akhbar Al-Khaleej (27\%). The two newspapers, Al-Watan and Al-Bilad have scored less than $15 \%$. News websites of BNA and Al-Wasat

\footnotetext{
${ }^{2}$ It is to be pointed out that the events that took place in the Kingdom of Bahrain in 2011, which were marked by conflicts of news on the Internet and the spread of rumors and antirumors about the development of the political and security situation, have made most people cautious in the use of online news, because they believe that some of the news websites lack credibility in their publication.
} 
and Al-Ayam newspapers benefit from their superiority over the other websites in terms of popularity and success of their accounts on social media networks among young users in Bahrain. The content of the Bahraini news websites is not different from what is published by the same newspapers in the printed version. There is no process or treatment to the digital content or a strategy targeting users on the electronic version in accordance with the norms and standards of digital media writing and production (Brian, 2014). These websites do not reflect the new systems for content production that allow the creation of broader patterns for building information on the Internet (Boczkowski, 2002).

There are so far no scientific studies that explain the business model adopted by the media outlets in the Kingdom of Bahrain or analyze the issue of reliance on the new elements of income, which can be beneficial through pre-payment to access the archives or direct advertising through free subscription to some digital services and even paid subscriptions to some digital services (Dagiral \& Parasie, 2010). As for international news websites, they have not been able to succeed in attracting the largest number of users, compared to the local newspaper websites, as Al-Jazeera Net and Al-Arabiya Net scored less than $15 \%$, and the news website of Al-Sharq Al-Awsat newspaper only 5\%. The result, which is striking, is that the respondents were not interested in the Al-Arab newspaper published in London $(0 \%)$. It seems that this result is related to the lack of a printed copy of Al-Arab newspaper, to be distributed in Bahrain like other international newspapers.

It is clear from the percentage of the news websites used by young adults in the Kingdom of Bahrain, who are basically "local," that they are interested more in local events, and much less in international news. An important result that can be shown is that the respondents mentioned other news websites and sources they use, not included in the proposed list, the most important of which are social media networks, news applications in Arabic such as "Nabdh" (News aggregator for a number of Arabic-language local and international news), the BBC Arabic online, and some local and international news websites in English. The use of social media via the smartphone, as sources of news is an important indicator that supports the results of a study by the Reuters Institute for Digital News (Newman et al., 2016) in which $51 \%$ of respondents reported using social media as a source of news weekly.

Table 2. Using News Websites

\begin{tabular}{|l|c|c|}
\hline & Frequency & Percent \\
\hline Bahrain News Agency (bna.bh) & 188 & 47 \\
\hline Al-Wasat (alwasatnews.com) & 176 & 44 \\
\hline Al-Ayam (alayam.com) & 160 & 40 \\
\hline Akhbar Al-Khaleej (akhbar-alkhaleej.com) & 108 & 27 \\
\hline Al-Watan (alwatannews.com) & 60 & 15 \\
\hline Al-Bilad (albiladpress.com) & 40 & 10 \\
\hline Al-Arabiya (alarabiya.net) & 68 & 17 \\
\hline Al-Jazeera (aljazeera.net) & 60 & 15 \\
\hline Al-Sharq Al-Awsat (aawsat.com) & 20 & 5 \\
\hline Al-Arab (alarab.co.uk) & 0 & 0 \\
\hline Other & 164 & 24 \\
\hline
\end{tabular}




\section{Less Time to Read, More Time to Browse}

Smartphones are unrivalled among the most important and greatest devices commonly employed in the use of online news by young adults in Bahrain (97\%), far ahead of the computer (24\%) and the Tablet (8\%). This result is similar to the findings of previous studies that showed that the mobile phone is the most important method to receive news among students in the universities of the Gulf (Zayani et al., 2015). This finding also supports the high percentage (131.8\% per 100 inhabitants) for the subscription of Bahrainis in general to the Internet via smartphone (ITU, 2015).

Increased ownership of smartphones supports the concept of what became known as the constantly developing "digital dynamic culture" especially among young adults (Lardellier, 2006). The smartphone with its various applications and services has become a part of the personal memory for keeping numbers, an address book, and a tool for retrieving sentimental memories through photos, video and SMS. It is also a way to read and record the "first version" of history through following, interacting and sharing the online news with others.

With regard to the preferred time for the use of online news, results show that is almost at all times among young adults in Bahrain with higher percentages in the morning (51\%) and the evening (48\%), and less in the afternoon (26\%). The extensive use of online news by young adults seems to be supported by the extensive use of the smartphone that is provided with Internet service. The low use in the afternoon can be explained by the cultural and sociological nature of the Arabian Gulf region habit of napping at this particular time due to the hot and humid weather conditions ${ }^{3}$.

Young adults in Bahrain use online news largely at home (86\%). Other places scored only low percentages such as the place of study $(23 \%)$ and the place of work (16\%). Some of the respondents also said they use online news in other places such as cafes, restaurants and other public places.

As for the duration of use, the vast majority of respondents (62\%) allocate less than an hour a day to online news, and about one-third of the respondents devote an hour to two hours a day (35\%), while a remaining small category (3\%) use online news between two and three hours a day. This result confirms a new characteristic of young adult Internet users in general, who belong to a new generation of users, the so-called "the interacting" (Brian, 2014) or "digital generation" (Livingstone, 2003). They are characterized by allocating less time to reading on the screen, and more time to browsing news, participating and interacting with others (Table 3).

\footnotetext{
${ }^{3}$ Work in the ministries and government institutions in the Kingdom of Bahrain starts at seven o'clock in the morning and finishes at two o'clock in the afternoon due to the hot and humid weather conditions in the Arabian Gulf region.
} 
Vol. 4, No. 1 Alsridi: Uses and Gratifications of Online News among Young Adults...

Table 3. Device Type, Time of Day, Duration and Location for the Use of Online News

\begin{tabular}{|c|c|c|}
\hline & Frequency & Percent \\
\hline \multicolumn{3}{|l|}{ Type of device } \\
\hline Smartphone & 380 & 97 \\
\hline Tablet & 96 & 24 \\
\hline Computer & 32 & 8 \\
\hline \multicolumn{3}{|l|}{ Time of day } \\
\hline Morning & 204 & 51 \\
\hline Evening & 192 & 48 \\
\hline Noon & 104 & 26 \\
\hline \multicolumn{3}{|l|}{ Place } \\
\hline Home & 340 & 87 \\
\hline Place of study & 92 & 23 \\
\hline Place of work & 64 & 16 \\
\hline Other & 36 & 9 \\
\hline \multicolumn{3}{|l|}{ Duration } \\
\hline Less than hour & 244 & 62 \\
\hline $1-2$ hours & 140 & 35 \\
\hline $2-3$ hours & 12 & 3 \\
\hline
\end{tabular}

\section{Particular Interest in Local and National News}

In response to the question on the importance of online news by type (local, political, economic, cultural, scientific, medical, social, international), the respondents said they substantially benefitted from the use of online news in all types. Users expressed greater interest in local news (50\% very useful and $42 \%$ useful), as well as political and national news (37\% very useful and 54\% useful). This is in line with the preference for news websites of local newspapers and BNA (Table 2). On the other hand, respondents expressed weak interest in economic news (24\% not useful and $13 \%$ not at all useful) as well as scientific and medical news (15\% not useful and $10 \%$ are not at all useful) (Table 4).

Table 4. Importance of Online News by Type

\begin{tabular}{|c|c|c|c|c|c|c|c|c|c|}
\hline & \multicolumn{2}{|c|}{ Very useful } & \multicolumn{2}{|c|}{ Useful } & \multicolumn{2}{|c|}{ Not useful } & \multicolumn{2}{|c|}{ Not at all useful } & \multirow[t]{2}{*}{ Mean } \\
\hline & $\mathbf{N}$ & $\%$ & $\mathbf{N}$ & $\%$ & $\mathbf{N}$ & $\%$ & $\mathbf{N}$ & $\%$ & \\
\hline Local news & 196 & 50 & 168 & 42 & 24 & 6 & 8 & 2 & 3.40 \\
\hline National \& political news & 144 & 37 & 212 & 54 & 24 & 6 & 12 & 3 & 3.24 \\
\hline Social news & 144 & 38 & 180 & 47 & 48 & 13 & 12 & 3 & 3.19 \\
\hline International affairs news & 116 & 31 & 212 & 56 & 40 & 11 & 12 & 3 & 3.14 \\
\hline Cultural \& artistic news & 112 & 29 & 176 & 46 & 76 & 20 & 20 & 5 & 2.99 \\
\hline $\begin{array}{l}\text { Scientific and medical } \\
\text { news }\end{array}$ & 108 & 28 & 180 & 47 & 56 & 15 & 40 & 10 & 2.93 \\
\hline Economic news & 52 & 14 & 188 & 49 & 92 & 24 & 48 & 13 & 2.64 \\
\hline
\end{tabular}




\section{Motivations of Use Based on the Freedom of Choice and Easy Access to News}

There are three main reasons behind young adults' use of online new in Bahrain: (1) easy access to online news, (2) the ability to access the news at any time, and (3) access to news updates at any time (Table 5).

Table 5. Reasons for the Use of Online News

\begin{tabular}{|l|c|c|c|c|c|c|c|c|c|c|c|}
\hline & \multicolumn{2}{|c|}{$\begin{array}{c}\text { Strongly } \\
\text { agree }\end{array}$} & \multicolumn{2}{|c|}{ Agree } & \multicolumn{2}{c|}{$\begin{array}{c}\text { Neither agree } \\
\text { nor disagree }\end{array}$} & \multicolumn{2}{|c|}{ Disagree } & \multicolumn{2}{|c|}{$\begin{array}{c}\text { Strongly } \\
\text { disagree }\end{array}$} & Mean \\
\hline & $\mathbf{N}$ & $\mathbf{\%}$ & $\mathbf{N}$ & $\mathbf{\%}$ & $\mathbf{N}$ & $\mathbf{\%}$ & $\mathbf{N}$ & $\mathbf{\%}$ & $\mathbf{N}$ & $\mathbf{\%}$ & \\
\hline They are easy to access & 260 & 68 & 116 & 30 & 8 & 2 & 0 & 0 & 0 & 0 & 1.34 \\
\hline $\begin{array}{l}\text { Because I can access } \\
\text { the news whenever I } \\
\text { want }\end{array}$ & 264 & 68 & 92 & 24 & 20 & 5 & 12 & 3 & 0 & 0 & 1.43 \\
\hline $\begin{array}{l}\text { Because I can get } \\
\text { updated news } \\
\text { whenever I want }\end{array}$ & 232 & 62 & 112 & 30 & 12 & 3 & 12 & 3 & 4 & 1 & 1.51 \\
\hline $\begin{array}{l}\text { Because I can get the } \\
\text { news that interest me }\end{array}$ & 208 & 55 & 156 & 41 & 8 & 2 & 4 & 1 & 4 & 1 & 1.53 \\
\hline $\begin{array}{l}\text { Because I can get the } \\
\text { news while doing } \\
\text { other work on the } \\
\text { Internet }\end{array}$ & 192 & 51 & 140 & 37 & 28 & 7 & 20 & 5 & 0 & 0 & 1.67 \\
\hline $\begin{array}{l}\text { Because I find a } \\
\text { variety of opinions on } \\
\text { the Internet }\end{array}$ & 180 & 46 & 132 & 34 & 52 & 13 & 16 & 4 & 12 & 3 & 1.85 \\
\hline $\begin{array}{l}\text { Because I have better } \\
\text { options for news on } \\
\text { the Internet }\end{array}$ & 164 & 43 & 160 & 42 & 48 & 13 & 8 & 2 & 4 & 1 & 1.77 \\
\hline $\begin{array}{l}\text { Because I can } \\
\text { participate and } \\
\text { express an opinion on } \\
\text { the news }\end{array}$ & 148 & 39 & 124 & 33 & 68 & 18 & 36 & 9 & 4 & 1 & 2.01 \\
\hline Because it is free & 132 & 34 & 160 & 41 & 28 & 7 & 44 & 11 & 24 & 6 & 2.14 \\
\hline
\end{tabular}

There are other reasons, which occur at a lower rate, for such media use, the most important of which are access to news of interest to the user only, access to the news at the same time as doing other work on the Internet, as well as participating and expressing one's opinion about the news on the Internet.

The free news issue on the Internet was not given great importance by the respondents, possibly because of the lack of clear business models for online news in general in Bahrain, which provide free and non-free news services, similar to some media outlets in Europe and North America (Dagiral \& Parasie, 2010).

\section{More Browsing than Reading of News by the User}

In response to the question: What are the tools used to optimize the use of online news, the overwhelming majority of respondents said they use search engines to access the news that interest them $(82 \%)$. Some of them shared in 
mailing lists of breaking news according to their interests (21\%), while a small number $(10 \%)$ reported they created a special folder for news websites that they use within a web browser.

The issue of consistently high rates of use of search engines for online news agrees with the global averages in the use of search engines in general to search for information and data. Google search engine gets over $90 \%$ of searches around the world (Worldwide Desktop Market Share, 2016).

It is confirmed once again that social media networks have become a major channel used to access news and discussion on the Internet (Newman et al., 2016). Most of the respondents (52\%) said they discuss the news through participation in social networks.

A significant number of respondents also reported that they send news links to others (38\%), and receive links from others (36\%). Commenting on the news, or what is also called micro-blogging, is considered one of the important activities (28\%), while participation in online polls represents only a small percentage (9\%), and participating in discussion forums about the news is barely an important activity (4\%). This may be due to the development of web technology that provides space to interact with news in an integrated manner through direct comments on the news and re-interaction around the same comment. Thus, interaction and participation in various patterns on news websites have become essential activities for users, which may quickly lose its significance in the absence of continued collaboration (Lardellier, 2006).

Table 6. Patterns of Use and Participation in News Websites

\begin{tabular}{|c|c|c|}
\hline & Frequency & Percent \\
\hline \multicolumn{3}{|l|}{ Tools of Use } \\
\hline I use search engines to access the news that interests me & 316 & 82 \\
\hline I subscribe to the news mailing lists based on my interests & 80 & 21 \\
\hline I create a my news pages folder in the browser & 40 & 10 \\
\hline \multicolumn{3}{|l|}{ Types of Participation } \\
\hline I participate in social media networks around specific news & 200 & 52 \\
\hline I send news links to others & 148 & 38 \\
\hline I receive news links from others & 140 & 36 \\
\hline I subscribe to news comments & 108 & 28 \\
\hline I take part in electronic opinion polls & 36 & 9 \\
\hline I participate in the discussion forums about certain news & 16 & 4 \\
\hline \multicolumn{3}{|l|}{ Patterns of Use } \\
\hline I brows the news more than read it & 288 & 75 \\
\hline I use video news & 192 & 50 \\
\hline I use audio news & 48 & 13 \\
\hline I print out some news to read later & 24 & 6 \\
\hline
\end{tabular}

It seems that young adults in Bahrain browse news websites more than read them $(75 \%)$. This is due to behavioral patterns, regarding the same new features for the young Internet user, who reads less on the screen; devotes less time for online news (62\% of the respondents allocate less than one hour per day), and prefers to read short texts and use multimedia tools. 
Video news is considered one of the most widely used multimedia patterns among young users $(50 \%)$, as it is very popular both at the same news websites and on social media networks. Furthermore, it is easy to share with others because of the short duration, which matches the speed feature that distinguishes the new behavior of the young user on the Internet. News audio is used less among young users $(12 \%)$, and these young adults have turned into users not interested in print, as only $(6 \%)$ print out the news after reading it (Table 6).

\section{The Internet as the Most Important Source of News and the Mobile Phone Applications for Breaking News}

In response to a question on how to get the latest news, most respondents agree that the Internet is the first method to use for the latest news (67\%). In addition, $40 \%$ of the respondents indicated that they visit news websites more than once a day for news and updates. This necessarily means that new behavior towards the news generally appears as a result of its being free, accessible and constantly updated.

Another finding confirms what has been said previously: the mobile phone is the greatest tool used as a source of breaking news on the Internet. The majority of respondents reported that their access to news is through the use of an application on the mobile phone (72\%). There are a large number of news applications that are used for this purpose, most notably the application of "Nabdh," well known in the Arab world as a news aggregator of hundreds of news websites in Arabic, as well as mobile media applications that are usually developed by the same media outlets or independent developers.

In a smaller percentage, young adult users in Bahrain receive breaking news on the Internet by saving the site page in the favorites (30\%), and by subscribing to the breaking news mailing list $(10 \%)$. The low percentage of users on breaking news mailing lists may be explained by the potential inconvenience caused by the ads in the user's e-mail, or matters related to the user's privacy when using his email.

Not only do Bahraini young adults read or use online news, but also use additional tools to increase their information about specific news. One of these tools is to visit other websites in order to view the same news (48\%). This may mean that they are keen to check the authenticity of the news and its credibility from different sources or compare the news offering via different news websites. Users will also click on relevant news to deeply view the news (47\%). This behavior is a reflection of an active user who wants to broaden his knowledge of the news. However, the problem is that most of the relevant links are archival news or data belonging to the same website or prepared by the editors. This type of user embodies the essence of the theory of uses and gratifications that puts the user at the top of the communication process. Many researchers have called attention to the impact of technological developments on the "gatekeeping" process, which is a major process in the work of the mainstream media. With the rapid development of online publishing and new editorial functions, the concept of "gateopening" 
process has been emerged (Boczkowski, 2002). This new concept is based on the facilitation of content production via internet networks.

With the emergence of "We Media" (Bowman and Willis, 2003), the traditional dominance of the media has gradually faded away as a major source of news, not only because of the technological development and increased competition, but also because of its audience, which is armed with online publishing tools and continuous network connectivity, and thus becomes an active user in the production and publishing of news and information.

Unlike the previous active behavior patterns, a small percentage of users $(30 \%)$ turn to media other than the Internet for further information about the news. The result may reflect a new fact in the world of online news that the user has become a prisoner of the network, which is full of rich tools and spaces for accessing the news, but does not push the user to return to the mainstream media such as the printed newspaper, radio or television. Thus, it may create a kind of "passive user" who does not come out of the Internet loop, as a communication tool, which is almost closed.

Table 7. Sources of Accessing News and Obtaining More Information About It

\begin{tabular}{|l|c|c|}
\hline \multicolumn{2}{|l|}{ Frequency } & Percent \\
\hline Sources of access to the latest news & 252 & 67 \\
\hline I use the Internet as the first tool to see what happened & 152 & 40 \\
\hline I visit news websites more than once a day & 280 & 72 \\
\hline Sources of access to breaking news & 116 & 30 \\
\hline Through an application in the mobile phone & 40 & 10 \\
\hline I save the website page in the favorites & 184 & 48 \\
\hline I subscribe to a news mailing list & 180 & 47 \\
\hline Sources of gaining more information about the news & 30 \\
\hline I visit other websites for more information on the same news & 116 & \\
\hline I click on relevant news to get a closer look at the news & $\begin{array}{l}\mid \\
\text { I search for sources other than the Internet for more } \\
\text { information on the news }\end{array}$
\end{tabular}

Furthermore, Lardellier (2006) spoke of the "tyranny" of maintaining Internet access and a "reluctance" to get out, considering that the development of Internet technologies, which are developing and advancing, gives the impression to users who decide to end their connection to the Internet that they will "bear the responsibility of terminating the connection and exiting from the network" (Table 7).

\section{Ads Limit the Success of the User's News Experience}

In answering the question "How do you describe yourself when browsing the news on the Internet," it seems that the problem of the appearance of ads is the biggest obstacle to the user in accessing the online news. Most respondents say they find themselves frustrated by the ads included in the body of the news. This finding is consistent with the results of previous studies that indicate the user's frustration when using online news (Nguyen et al., 2005). The user's frustration is shown, especially with the news on mobile phone applications, as the user often 
finds himself waiting from 5 to 20 seconds, during which time he or she is forced to view video ads before accessing the news.

The issue of caution about the validity and credibility of the news seems to be one of the most important reasons that lowers the success of the user's online news experience as the user finds himself confronted by false or incorrect news. This issue is even more important for young adult users in Bahrain as a result of the climate of mistrust that dominated the Bahraini society in its relationship with the local and international media in general following the events of 2011, where there was conflicting news from the mainstream or electronic media, local or international, on the political situation at that time. The BBC Trust Report (2012) admitted that BBC Arabic and its news network needed more "investigation and understanding of the context" when publishing and analyzing the political and security developments in Bahrain in 2011, as well as other countries in what is known as the "Arab Spring." A local Bahraini newspaper was also banned from publication in the same year and sued for "non-professional acts" intended to publish false news about events in Bahrain in 2011 (BNA, 2011).

On the other hand, some users have turned their online experience into a bad experience because of being angry or insulted during exchanges of views on the news. The question of having users in front of a large number of news is described as a matter that creates a state of loss, thus lowering the success of the news experience for the user.

Table 8. User Behavior Towards Online News

\begin{tabular}{|c|c|c|c|c|c|c|c|c|c|}
\hline & \multicolumn{2}{|c|}{ Always } & \multicolumn{2}{|c|}{ Sometimes } & \multicolumn{2}{|c|}{ Very often } & \multicolumn{2}{|c|}{ Never } & \multirow[b]{2}{*}{ Mean } \\
\hline & $\mathbf{N}$ & $\%$ & $\mathbf{N}$ & $\%$ & $\mathbf{N}$ & $\%$ & $\mathbf{N}$ & $\%$ & \\
\hline $\begin{array}{l}\text { I find myself frustrated by the ads } \\
\text { included in the news body }\end{array}$ & 124 & 33 & 88 & 23 & 128 & 34 & 40 & 11 & 2.78 \\
\hline $\begin{array}{l}\text { I find myself in an angry or } \\
\text { insulting position when } \\
\text { exchanging views about the news }\end{array}$ & 36 & 9 & 76 & 20 & 168 & 44 & 100 & 26 & 2.13 \\
\hline $\begin{array}{l}\text { I find myself lost due to a large } \\
\text { number of news }\end{array}$ & 24 & 6 & 48 & 12 & 256 & 68 & 60 & 15 & 2.05 \\
\hline $\begin{array}{l}\text { I find myself seeing false or } \\
\text { wrong news }\end{array}$ & 24 & 6 & 80 & 21 & 248 & 65 & 32 & 8 & 2.25 \\
\hline $\begin{array}{l}\text { I missed important news after } \\
\text { browsing Internet websites }\end{array}$ & 16 & 4 & 76 & 20 & 204 & 54 & 80 & 21 & 2.07 \\
\hline $\begin{array}{l}\text { I find myself tired of reading the } \\
\text { news on the screen }\end{array}$ & 16 & 4 & 88 & 23 & 168 & 45 & 104 & 28 & 2.04 \\
\hline
\end{tabular}

Although the Internet with all its diverse sources provides various tools and methods to access the news, some respondents believe that there is important news that has been absent after a long tour of visiting the websites. This result is very significant because it revives the debate on "Agenda Setting" theory. Many researchers in communication consider that the theoretical pillars upon which the subject is built may not apply to electronic media, including news websites, which have been opened to all users and have thus contributed to the revision of the socalled "Gatekeeper" term (Boczkowski, 2002), in front of a huge number of news, 
information, data and other sources from which the user can benefit. However, this vast amount of information and resources may have negatively impacted the experiences of users, who can be said to have "got things and missed things," although they believe that they have the tools to own them.

Describing their behavior towards the use of online news, fewer respondents experienced a feeling of fatigue in front of the screen in general after using the news. This finding is consistent with most studies on screen uses on the Internet, which indicate that screens make us read slower, learn less deeply, remember less and sleep worse (Nielsen, 1999; Myrberg \& Wiberg, 2015) (Table 8).

\section{New Generation of Users Favor Freedom and Control of Use Tools}

In response to an open question about assessing the user experience in using online news in general, all young adult respondents in Bahrain who stated that they are using online news agree that "the Internet is the fastest and best way to share and search for news without limits to expressing one's personal opinion." It is also accessible, "quick, available at all times and more neutral in terms of multiple opinions on the same subject." It also makes the user "control the use of the news and be able to enter, exit, read and publish anywhere and at any time" (Ruggiero, 2000). Others said they prefer receiving news links or links to analyzing the news, which are ways of "winning time and saving effort in searching for news." However, this behavior may make the user a non-independent one, because of using only what others suggest through links.

Respondents say that social media networks and smartphone applications are among the top sources for online news, a result confirmed by the Newman et al. (2016). On the other hand, others warn of "the spread of hatred and offensive content that can arise in the climate of freedom and expression of opinion that is difficult to monitor on the Web". This is a "double-edged sword" that we must exercise care when using (Livingstone, 2003). The following are the exact words said by a respondent, "The online news is something nice for me because it enables me to see the latest news whenever I want and at any time that suits me. There is a variety of news, but there are many drawbacks such as the fallacy in the news or the falsification of events". Others argue that "newspapers should develop the content of their news websites so that they can compete with social networking sites, otherwise they become non-existent" (Dagiral \&Parasie, 2010).

Thus, the use of online news by young adults in Bahrain reflects a sense of belonging to the user community (Breton \& Proulx, 2002) through which they carry out multiple media activities that go beyond the traditional reading of the news on the screen. These reflect the user's active behavior, which is not limited to receiving what is published or sent to him by the news, but rather allows him to choose what satisfies his needs and interacts with what suits him or with those who interact with him.

Finally, the researcher did not find any significant correlations between gender, educational level or profession, in the analysis of the online news consumption by young adults in Bahrain. 


\section{Conclusion}

The results of the field study show that the percentage of interest in online news by young adults in the Kingdom of Bahrain is high, despite the presence of other mainstream media. In this study, respondents expressed greater interest in local or national news, compared with international affairs. The local news websites of BNA, Al-Wasat and the Al-Ayam newspapers have the highest percentage of use, although they do not rely on a strategy for editing or providing digital services other than the paper version (Dagiral and Parasie, 2010). The success of these news websites in attracting Bahraini young adults may be attributed to the popularity of their accounts on social media networks.

It seems that the Bahraini young adult is very active on the Internet, especially with mobile phones at all times and in all places. However, he is a fast user, who often devotes less than an hour a day to using online news. The Bahraini young adult describes online news sites as useful or very useful in providing users with news in all local, political, social, cultural and artistic fields, however, he says that he benefits less from the economic, medical and scientific news.

The reasons given by Bahraini young adults for their use of online news fall mainly under the concepts of freedom and control of tools of use.

From the perspective of uses and gratifications theory, it is clear that the Bahraini young adult user appears to be an active user who employs the Internet technologies available to practice many media activities related to news websites and satisfy his needs (Ruggiero, 2000). He uses search engines to access the news he is interested in, and is heavily involved in social media networks about the news, but he brows news more than he reads it, with a greater focus on the use of video news (Brian, 2014).

For the user, the Internet is the first way to know that an event took place, but he does not just read about it. He visits other websites or clicks on relevant links to increase his knowledge. As a result of this strong connection between the user and the online news, through using other websites or clicking relevant links, it is clear that the smartphone is playing the main role in this relationship, through the provision of media applications for breaking news, which in turn is a good input to promote user activity in the use of the Internet in general.

Despite the intense activity or use of online news by the Bahraini young adult user, he has often been disturbed by some difficulties that impede the completion of a successful news experience and the achievement of real satisfaction from use. Forced advertising, especially in the news body, remains the main obstacle to gratifications, especially in mobile news applications that often impose a few seconds of video ads before accessing the news.

In general, the study has found that young adults users in Bahrain are increasingly associated with the use of online news, creating a new social and cultural reality (Lardellier, 2006), which was further enhanced by the unprecedented use of smartphone applications by young adults in recent years. Online news and smartphone applications may be an additional route for young adults in Bahrain to create new spaces for freedom and expression of opinion (Alsridi, 2010), thanks to the flexibility of their communication, engagement and interaction mechanisms. 


\section{References}

Alshehri, A. F. (2000). Electronic Newspapers on the Internet: A Study of the Production and Consumption of Arab Dailies on the World Wide Web (Unpublished doctoral dissertation). University of Sheffield, UK. Retrieved from goo.gl/ySdl4M.

Alsridi, H. (2010). Usages de l'Internet par les Jeunes Bahreïniens: A la Recherche de Nouveaux Espaces d'Expression (Usages of Internet by Jeunes Bahreïniens: The Recherche de Nouveaux Espaces d'Expression). In Proceedings of the International Conference on Jeunes, Communication et Medias, Tunis, Tunisia, April 14-16, 2000.

Alsridi, H. (2001). La télévision Arabe par Satellite: Acteurs, Enjeux et Pratiques. Cas de la Réception des Chaînes Arabophones par Satellite par les Populations Maghrébines en France (Arab Satellite Television: Actors, Issues and Practices. Case of the Reception of the Arabophone Satellite Channels by the Maghreb populations in France) (Unpublished doctoral dissertation). University of Sthendal, Grenoble, France.

Arab Youth Survey. (2016). Inside The Hearts and Minds of Arab Youth - A White Paper on the Findings of the ASDA'A Burson-Marsteller. Retrieved from goo.gl/ ffEK80.

Arnett, J. J. (1995). Adolescents' uses of media for self-socialization. Journal of Youth and Adolescence, 24(5), 519-533.

BBC. (2012). A BBC Trust Report on the Impartiality and Accuracy of the BBC's Coverage of the Events Known as the "Arab Spring". Retrieved from goo.gl/31PgG6.

BNA. (2011). Bahrain Suspended Al-Wasat Newspaper for Publishing Unethical and Unprofessional Reports. Retrieved from goo.gl/wMuEij.

Blumler, J. G. \& Katz, E. (1974). The Uses of Mass Communications: Current Perspectives on Gratifications Research. Beverly Hills, CA: SAGE.

Boczkowski, P. (2002). The Development and Use of Online Newspapers: What Research Tells Us and What We Might What to Know. The Handbook of New Media (pp. 270-286). London: SAGE.

Bowman, S., \& Willis, C. (2003). We Media: How Audiences are Shaping the Future of News and Information. A Seminal Report. Reston: The Media Centre at the American Press Institute. Retrieved from goo.gl/FosEYN.

Breton, P., \& Proulx, S. (2002). L'Explosion de la Communication à l'Aube du XXIème siècle (The Explosion of Communication in the Dawn of the 21st Century). Paris: La Découverte.

Brian, C. (2014). Writing \& Editing for Digital Media. London: Routledge.

Chyi, H., \& Larosa, D. (1999). Access use and preferences for online newspapers. Newspaper Research journal, 20(2), 2-13.

Dagiral, E., \& Parasie, S. (2010). Presse en Ligne: Où en est la recherche? (Online Press: Where is the search?). Réseaux, 28(160-161), 13-42.

Dominique, P. (1994). Vingt Ans de Recherches sur la Télévision: Une Sociologie Post Lazarsfeldienne? (Twenty Years of Television Research: A Post Lazarsfeldian Sociology?). Sociologie de Travail, 37(1), 63-84.

Elareshi, M., Ziani, A., \& Gunter, B. (2014). How GCC University Students Get Local News and Information. Studies in Media and Communication, 2(2). Retrieved from goo.gl/ftwSbj.

Elliott, W. R., \& Rosenberg W. L. (1987). The 1985 Philadelphia newspaper strike: A uses and gratifications study. Journalism Quarterly, 64(4), 679-687.

Information \& E-Government Authority. (2016). Bahrain Open Data Portal. Retrieved from https://goo.gl/TqZLvz. 
ITU. (2015). Bahrain Profile. Retrieved from goo.gl/W6hJQf.

Lardellier, P. (2006). Le Pouce et la Souris, Enquête sur la Culture Numerique des Ados (The Thumb and the Mouse, Survey of the Numerical Culture of Teens). Paris: Fayard.

Lin, C. A. (1999). Uses and Gratifications. In G. Stone, M. Singletary, \& V. P. Richmond (Eds.), Clarifying Communication Theories: A Hands-on Approach. Ames, IO: Iowa State University Press.

Livingstone, S. (2003). Children's Use of the Internet: Reflections on the Emerging Research Agenda. New Media \& Society, 5(2), 147-166.

Media Use in the Middle East. (2016). Northwestern University in Qatar. Retrieved from goo.gl/N7X0Kk.

Meeds, R. (2015). Changing Roles of Traditional and Online Media as Trusted News Sources in Qatar and Their Relationships With Perceived Important Issues and Interest in Politics. Journal of Middle East Media, (11), 34-61.

Myrberg, C., \& Wiberg, N. (2015). Screen vs. paper: what is the difference for reading and learning?. Insights, 28(2), 49-54.

Newman, N., Fletcher, R., Levy D., \& Kleis, R. (2016). Reuters Institute Digital News Report 2016. Reuters Institute for the Study of Journalism. Retrieved from goo.gl/ f1yYkf.

Nguyen, A., Ferrier, E., Western, M., \& Mcky, S. (2005). Online News in Australia: Patterns of Use and Gratification. Australian Studies in Journalism, (15), 5-34.

Nielsen, J. (1999). Designing Web Usability: The Practice of Simplicity. Indianapolis: New Riders Publishing.

Reyaee, S., \& Ahmed, A. (2015). Growth Pattern of Social Media Usage in Arab Gulf States: An Analytical Study. Social Networking, (4), 23-32.

Roberts, D. F., \& Foehr, U. G. (2004). Kids and Media in America. Cambridge: Cambridge University Press.

Ruggiero, T. (2000). Uses and Gratifications Theory in the 21st century. Mass Communication \& Society, 3(1), 3-37.

The World Internet Project. (2016). International Report, Sixth Edition. University of Southern California. Retrieved from goo.gl/iZUCLk.

Understanding the Arab Digital Generation. (2012). Strategy \& Retrieved from goo. $\mathrm{gl} / \mathrm{dq} 9 \mathrm{c} 6 \mathrm{i}$.

Worldwide Desktop Market Share of Leading Search Engines from January 2010 to January 2017. (2016). Statista. Retrieved from goo.gl/z2Wwp9.

Zayani, A., Elareshi, M., \& Gunter, B. (2015). The Use of Mobile Phone and the Internet in Obtaining Local News in GCC Regions: University Students' Perspectives. Donnish Journal of Media and Communication Studies, (1), 1-10. 
